\title{
Globalidad, modernidad y movimientos sociales: China y Asia Oriental frente al colonialismo europeo (1850-1900) ${ }^{1}$
}

\author{
Eduardo Madrigal Muñoz \\ Escuela de Estudios Generales \\ Escuela de Historia \\ Universidad de Costa Rica
}

\begin{abstract}
Resumen
Desde la óptica de la Historia Global y Mundial, el autor se propone analizar cinco movimientos sociales en países asiáticos influenciados por potencias imperialistas europeas en el siglo XIX, y establecer la relación entre ellos con respecto a procesos sociales internacionales, a procesos imperiales de expansión y a procesos de difusión de la globalización.
\end{abstract}

Palabras claves: revueltas sociales, imperialismo, Asia Oriental, modernidad

\begin{abstract}
From the point of view of the World Global History, the author of this article analyzes five social disturbances in Asian countries influenced by European imperialistic powers in the XIX ${ }^{\text {th }}$ century, in order to establish the relationship between them with regard to international and social processes, imperialistic expansionist processes, and the spread of globalization processes.
\end{abstract}

Key words: social disturbances, imperialismo, Eastern Asia, modernity

I.

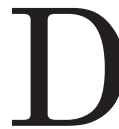
urante las últimas décadas, los procesos asociados a la así llamada "globalización" han tenido numerosas consecuencias de nivel mundial. Sin embargo, ha sido la globalización cultural -vinculada a todo un proceso de caída de paradigmas operado desde la pasada centuriala que ha tenido las consecuencias más significativas para detonar cambios $\mathrm{y}$ 
transformaciones en todo el campo de conocimiento de las Ciencias Sociales. Con ella, nuevas tendencias y escuelas de pensamiento han surgido a todo lo largo y ancho del campo de las Ciencias Humanas, algunas de las cuales nos motivan como temas fundamentales en el presente artículo. Nos referimos, muy en concreto, al estudio de la Historia Global y Mundial.

Con estas preocupaciones en mente, el objetivo que nos proponemos aquí es, en concreto, estudiar los movimientos sociales ocurridos en China y otras sociedades del Asia Oriental durante el alba de la modernidad y la expansión imperial europea sobre la región. Este estudio se ubicará dentro de las corrientes de pensamiento recientes de las Ciencias Sociales, que se han interesado por analizar los procesos sociales que se verifican en el nivel de lo mundial y lo global -identificadas bajo el apelativo de "World History"-, las cuales han estado motivadas por los procesos de globalización que han atravesado nuestras sociedades en tiempos recientes (Mazlish). Se pretende, por lo tanto, presentar una interpretación integral de algunas movilizaciones sociales de este período y región de estudio, pero no de cualquier manera ni mucho menos en la línea de los enfoques más tradicionales sino partiendo de los enfoques actuales de la Historia Mundial, ubicándolos por lo tanto en el contexto de los procesos mundiales de su época.

Nos proponemos analizar, en concreto, cinco revueltas sociales acaecidas en países asiáticos invadidos por potencias imperialistas durante el siglo XIX, con miras a estudiar la relación de todas ellas con procesos sociales de índole mundial, en primer lugar, con procesos imperiales de expansión glo- bal, pero también con procesos globales de difusión de la modernización, desde una perspectiva comparativa y de Historia Mundial. Las revueltas por analizar serán: el motín de los Cipayos de la India (1857), las revueltas de Taiping y de los Boxers de China (1851-1866 y 1899-1900), la rebelión de Dong-Hak de Corea (1894) y el incidente de Chichibu de Japón (1884).

La influencia de estos movimientos en la política de cada una de sus localidades y en su desenvolvimiento político y económico global y de las potencias imperialistas será la temática central del estudio. Una vez concretado este trabajo, los resultados de la investigación realizada pueden llegar a ser más que sorprendentes.

Tal estudio resulta indispensable -y como decimos, puede llegar a ser más que revelador- tanto más cuanto que, en la actualidad, el acelerado desarrollo y empoderamiento de los países asiáticos anuncia su posible transformación en potencias mundiales y el desplazamiento de los centros de poder del océano Atlántico al Pacífico. Pero además, el análisis de estos procesos no deja de provocarnos la intuición de que pueden tener una influencia determinante en el desarrollo de los debates y propuestas teóricas de las Ciencias Sociales, relativos a los procesos históricos globales de hoy. En ciertos ámbitos de los estudios históricos se ha venido hablando de un proceso conocido como "la Revolución Atlántica”, el cual -operado entre 1750 y 1850- habría destruido para siempre los viejos y agotados tejidos del Antiguo Régimen europeo para sustituirlos por el Estado Moderno y la Economía Industrial. El análisis del papel global de los países asiáticos en el período nos hace preguntarnos si no 
habrá también una "Revolución Pacífico-Índica" que quizá llevó también a los pueblos del Asia Oriental y Sudoriental hacia la modernización, es decir, a desplazar sus viejos esquemas como sociedades agrarias tradicionales y políticamente comunitarias y verticalistas, para construir un nuevo modo de vivir en civilización, como resultado del desafío y la intrusión en sus estructuras por parte de la modernidad occidental.

\section{II.}

¿Cuál es, pues, el contexto global en cuyas coordenadas nos orientamos? Era este definitivamente un mundo muy distinto del que conocemos hoy, pero que definitivamente no carecía de procesos mundiales y que ya estaba sin duda alguna en vías de convertirse en el que tenemos en la actualidad.

Vamos aquí a postular, como hipótesis de partida, que la génesis del contexto global en el que se situaron los procesos de imperialismo y resistencia que nos proponemos estudiar fue una gigantesca crisis, de extensión global. En efecto, a inicios del siglo XIX se produce toda una reestructuración del sistema-mundo creado en el siglo XVI, crisis que fue el resultado del colapso de la minería española, que había sido el pivote de la economía mundial por los trescientos años anteriores.

En efecto, ha sido señalado que la producción argentífera de los virreinatos ibéricos del Nuevo Mundo -junto, aunque en menor medida, con otros sistemas como el comercio triangular de esclavos conocido como la "Trata Atlántica"- era el elemento dinamizador que daba vida a las economías dominantes del mundo de entonces, léase la Europa del Antiguo Régimen y la China de las dinastías Ming y Qing. La circulación de las riquezas en plata entre estos tres mundos -producto del intercambio comercial existente entre ellos- era el eje motor del dínamo económico global (Tutino).

Sin embargo, aún con todo su poderío y su papel hegemónico mundial, este sistema habría de tocar su fin, el cual vendría de la mano con procesos revolucionarios, también de escala global. El ciclo de revoluciones iniciado por la independencia de las Trece Colonias inglesas de Nueva Inglaterra (hoy Estados Unidos, 1776), la Revolución Francesa de 1789, la Independencia de Haití (1799-1804), y las independencias hispanoamericanas (1810-1821), dislocaría severamente el armazón económico mundial centrado en la circulación de la plata americana y dejaría el orden mundial de las potencias dominantes en una severa recesión.

Ante este panorama, el vacío de poder dejado por el hundimiento de España como potencia mundial y de su imperio como pivote económico de la globalidad, pronto sería llenado en el sistema global por las ciudades industriales inglesas, entonces en pleno auge.

Como resultado de tal proceso, la economía y la geopolítica mundial se reestructurarían, pero ahora bajo un signo civilizatorio muy diferente. No será ya entonces bajo el signo del corporativismo y del absolutismo del Antiguo Régimen que se organicen las sociedades occidentales. Lo harán ahora bajo el estandarte de la industrialización y el Estado Moderno, es decir, bajo el signo de la modernidad. La Revolución Industrial británica emerge entonces y un nuevo sistema de relaciones globales liderado ahora por Inglaterra y 
conocido como la Pax Britannica tomará el relevo en la dirección de las relaciones internacionales.

Paralelamente, un proceso inverso de declive de las viejas potencias asiáticas se hará sentir. China y la India, antiguos poderes globales que habían ganado su condición de tales en función de su papel como emporios productores de té, sedas y porcelanas -tesoros altamente codiciados por los mercados europeos y pagados ¿cómo no? con plata americana- verán poco a poco perder su posición como potencias de orden mundial por la invasión de las manufacturas textiles británicas como producto de la Revolución Industrial.

Además, industria e imperio se van a complementar mutuamente de aquí en adelante, pues la industria necesitará del imperialismo para abrir mercados globales con el fin de colocar sus ahora abundantísimos productos. Como resultado, la potencia industrial británica -y a ello se sumaron luego las demás- se vio en la necesidad de llevar adelante procesos de apertura forzosa y de invasión pura y simple a los países asiáticos, antes potencias mundiales y en adelante convertidos en simples consumidores de las manufacturas occidentales, luego de ver su producción interna arruinada por la invasión de los productos europeos. Los acontecimientos principales que llevarán a la realización de este proceso de apertura forzosa son, esencialmente, las Guerras del Opio de 1839-42 y 1856-60 en China, la apertura de Japón por el comodoro Perry en 1853 (Tanaka 172-3), la llegada del acorazado General Sherman a Corea en 1866 (Hwang 118) y, por supuesto, desde mucho antes, la entronización de la Compañía Inglesa de las Indias Orientales como poder dominante en la India (Mishra 62). Este proceso de apertura forzosa desafió sustancialmente a las sociedades del continente asiático a replantear de todo a todo sus formas de producción (hasta entonces artesanales), sus sistemas de gobierno (de tipo monárquico-imperial), sus moldes mentales (signados por la tradición), así como sus estructuras sociales (ampliamente verticalistas y fundadas en el respeto por las jerarquías), por lo que se alteró, en definitiva, toda su forma de vivir en civilización.

Así, la construcción de una hegemonía mundial europea impacta en una reestructuración del sistema-mundo y por lo tanto en la globalidad, pero también conduce a un proceso de modernización forzado -a la adopción de moldes y maneras occidentales de ser y de hacer-, a las civilizaciones atacadas por el embate de esta transformación. El avance del imperialismo europeo (fase superior del capitalismo, como lo llamó Lenin) desafía con ello a estas sociedades a asumir la modernización o perecer (Ianni 59-74), y también lleva al estallido de movimientos sociales en toda el Asia Oriental y Sudoriental. Estos movimientos también tendrán efectos en toda la globalidad y actuarán para modificarla sustancialmente.

El cambio vendría, pues, de la mano con la invasión de los imperialistas occidentales, pero también con la crisis de la sociedad tradicional, de las sociedades del Antiguo Régimen europeas -que se transforman en sociedades modernas y en vista de ello invaden el mundo-, pero también de las sociedades dinásticas y señoriales de la dinastía Qing en China, de la dinastía Joseon de Corea, del Japón de los Tokugawa, así como de la India de los mogoles, confrontadas 
todas con el nacimiento de las sociedades modernas industrializadas y de los estados modernos occidentales, que las agreden y desafían. De hecho, algunos de los movimientos sociales cuyo estudio nos proponemos se gatillaron abiertamente en contra de los ya modernizados poderes imperiales europeos que los invadían, como manifestaciones de rechazo contra el proceso de imposición de valores modernos procedentes de Europa por sobre pueblos esencialmente no modernizados. Esto muestra, entre otras cosas, que la modernidad europea no fue difundida al mundo sin heridas.

Así pues, resulta claro que el imperialismo impuso un nuevo orden mundial (Hwang 119), pero también lo hicieron los movimientos sociales.

III.

Como hemos señalado, estos procesos fueron detonados por fenómenos globales, aunque también fueron impulsados por la transición de estas sociedades hacia la modernidad y contuvieron reacciones ya sea positivas o negativas hacia ella.

Todo esto nos hace entender la necesidad de elaborar una teoría que incluya los elementos vertebradores de estos procesos. En primer lugar, debemos recurrir a una perspectiva global que integre la relación Europa-Asia y Asia-Asia.

En segundo lugar, resulta fundamental contemplar una visión de larga duración que permita comprender la transformación de sociedades premodernas a modernas en un proceso de varios siglos de duración. Del mismo modo, es fundamental entender este cambio como una transformación profunda de la mentalidad colectiva, como un violento choque de las mentalidades tradicionales con los cambios que las modernizan.

Por ende, es también necesario estudiar el tema desde la perspectiva de un proceso de modernización que tome en cuenta elementos como la industrialización y la racionalización, pero también como la modernización del Estado, que pasa indudablemente por una secularización de los valores, así como por la aparición de conceptos tales como derechos sociales, igualdad y otros, que constituyen la ciudadanía moderna. Como veremos, en gran medida la gestación de estos procesos en las sociedades asiáticas fue impulsada no sólo por la influencia cultural que significaron las invasiones por parte del imperialismo europeo, sino también por la protesta social misma y por clamores sociales que estaban ya presentes en estos países. En este aspecto, el papel del género y de la religión en la sociedad y en los procesos de modernización resultan ser también elementos fundamentales que tomar en cuenta, pues estos procesos no dejan de lado el conflicto entre religiones o de las religiones con el pensamiento secular, como tampoco el lento avance en el empoderamiento social de la mujer.

De esta manera, es básico preguntarse: ¿hay influencia de los movimientos en los procesos globales? ¿la hay en sentido opuesto? ¿cuál es el papel de la modernidad en todo esto?

Para responder a estas preguntas, analizaremos los movimientos por estudiar en varias etapas. En primer lugar, estudiaremos en todos los casos cuáles son las causas de cada movimiento: veremos que en casi todos los 
casos, las revueltas fueron causadas por la invasión imperialista, que en esta época es predominantemente británica, aunque puede incluir a otras potencias también. Además, sucede que con frecuencia la invasión imperialista detona viejas tensiones sociales acumuladas contra los regímenes imperiales y contra las aristocracias senoriales predominantes.

En segundo lugar, analizaremos en cada caso cómo se desarrolla el movimiento en sí, cuáles son las características de los líderes, cuáles sus reivindicaciones, si son modernas o premodernas y, en suma, cuáles son sus características.

Finalmente, en todos los casos veremos cómo termina el conflicto, si este logra o no construir un proyecto modernizador, si triunfa o fracasa, si la globalidad y la modernización explican su desenlace y cuáles son sus implicaciones para lo global.

Distinguiremos, además, entre los movimientos por estudiar, la existencia de tres tipos de revueltas. El primero de ellos, el de la India, puede ser caracterizado como una explosión espontánea sin proyectos claros ni pro ni antimodernos, aun si su visión fue en principio premodernizante dado que buscó restaurar un orden predominante anterior a la intromisión británica, el cual estaba dado por una sociedad agraria, un gobierno monárquico y un orden social religioso y de castas.

En segundo lugar, tendremos las revueltas de China y Corea, que son básicamente revueltas premodernas en el sentido de que se apoyan en simbolismos y representaciones sociales propias de las sociedades tradicionales, las cuales buscan restaurar. Estas revueltas presentan, entonces, un afán por mantener las viejas estructuras de la sociedad agraria, el gobierno imperial y el orden social religioso, pero expurgándolas de los abusos, las iniquidades sociales y las violencias que se presentaban en su época por parte de los grupos gobernantes. Estos movimientos, además, tienden a entremezclar elementos reivindicativos significativamente modernos -probablemente por influencia de los procesos mundiales que se vivían en su época-, pero sin atinar a convertirlos en un proyecto transformador claro, y permaneciendo más bien en la confusión y la ambivalencia entre tradición y modernidad.

Un tercer tipo de movilización será el incidente de Japón que, contrario a todos los anteriores, más bien se presenta como una reacción de las multitudes desfavorecidas contra las políticas de modernización acelerada asumidas por el país, las cuales amenazaban con arrasar su estilo de vida tradicional.

\section{IV.}

Comenzamos entonces nuestro análisis con el estudio del primer tipo de revuelta social por examinar: el motín espontáneo premoderno.

\section{La Rebelión de los Cipayos, India, 1857}

Como en los otros casos que estudiamos aquí, este movimiento social -que se produjo en la India en 1857- fue una reacción contra el imperialismo británico, en particular contra los abusos de la Compañía Inglesa de las Indias Orientales. Estos abusos asumieron la forma, básicamente, de explotación, discriminación, corrupción, injerencismo 
político, conflictos con la cultura y la religión locales, procesos de occidentalización forzada, racismo y devastación de la economía interna de la India.

Esta compañía -base y fundamento del sistema colonial británico- se había establecido desde 1612 en la India y su objetivo era implantarse firmemente en el subcontinente, no sólo para apoderarse de sus mercados, sino también para ganar control político sobre extensas regiones (Mishra 62-4). Los cipayos (en inglés Sepoys) eran las tropas locales de la Compañía la que, con su fuerza militar, podía imponer su dominio económico sobre sustanciales porciones del territorio indio.

A partir de esta posición de fuerza, la Compañía echaba a andar vigorosos procesos de enriquecimiento, pero también enormes abusos contra la población, así como numerosos manejos corruptos. Por ejemplo, con el cobro de impuestos los oficiales de la Compañía se enriquecían de manera indebida a costillas de la población. Además, administraban mal los fondos recaudados y manejaban tiránicamente su relación con la población local, oprimiendo a los campesinos y sectores empobrecidos. Esto llevó a múltiples revueltas durante el siglo XVIII e inicios del XIX.

Por otra parte, las intromisiones políticas destinadas a asumir el mando del subcontinente no se hacían echar de menos. La Compañía destronaba príncipes y ponía otros en su lugar, de manera que incluso llegó a suplantar al mismísimo emperador mogol. Además, sus representantes firmaban tratados con los gobernantes locales para intervenir directamente en sus asuntos y así tener control económico y político sobre sus reinos. Este intervencionismo, por supuesto, era ampliamente rechazado por la población local (Mishra 66).

Pero allí no terminaba todo pues, además, las políticas de la Compañía entraban frecuentemente en conflicto directo con la cultura india. Por ejemplo, sus leyes eran lesivas para las costumbres indias y con frecuencia asumían tintes racistas, pues irrespetaban sistemáticamente asuntos fundamentales en la sociedad india como las barreras de casta, y excluían a los indios de la administración (Mishra 67). Además, los ingleses impusieron una dominación racista y una política de occidentalización de la India, pues autorizaron la llegada de misioneros para propagar el cristianismo e imponer la religión, al tiempo que interferían o abiertamente prohibían muchas costumbres indias (Mishra 67).

Por si esto fuera poco, la presencia colonial británica fue devastadora para la economía de la sociedad colonizada. La invasión de los textiles manufacturados británicos literalmente llevó a la quiebra la producción textil india -fundamentalmente artesanal-, lo que provocó que muchos artesanos tuvieran que emigrar al campo para dedicarse a la agricultura, con lo que saturaron el sector agrícola y produjeron su empobrecimiento. Como resultado, la Compañía no dudó en recrudecer la presión fiscal sobre los campesinos para mejorar sus ganancias al aumentar sus exigencias especialmente sobre las plantaciones de añil y té -las que buscaba controlar-, lo que agravó la situación del campesinado. De esta manera, agricultores y artesanos se hicieron hostiles a la Compañía (Mishra 67).

En este contexto, numerosas causas de descontento reinaban también en el ejército cipayo. La primera de ellas era 
la forma discriminatoria en que los británicos trataban a los soldados locales, pues, por ejemplo, no promovían a los indios más allá de ciertos rangos, les pagaban menos que a los oficiales ingleses, y con frecuencia los enviaban a fatigosas campañas en Birmania y Afghanistán (Mishra 68).

Con todo, la causa inmediata de la revuelta de los cipayos fue la introducción por parte de los ingleses de un nuevo fusil cuyos cartuchos eran lubricados con grasa de vaca y de cerdo. Esto causó el malestar de los soldados -que eran en su mayoría hindúes y musulmanes- ya que la vaca era un animal sagrado para los primeros, mientras que el cerdo era un animal prohibido para los segundos. Por ello, el uso de estos fusiles resultaba prohibido y chocante para los practicantes de ambas religiones ya que para cargarlos era necesario morder los cartuchos y luego verter su contenido dentro de las armas, siendo que para ambos credos era totalmente inaceptable llevarse a la boca nada que contuviera grasa de sus animales sagrados o prohibidos.

En este estado de cosas, hacia 1857 se empezaron a producir actos de desobediencia de los cipayos indios hacia los oficiales ingleses, llegándose incluso al asesinato de varios de ellos. Por estos actos, a muchos cipayos se les siguió consejo de guerra y fueron encarcelados (Mishra 69). El motín en concreto empezó entonces, pues otros cipayos liberaron a los cautivos y juntos marcharon sobre la ciudad de Delhi y la tomaron. Como una de sus primeras acciones y en desafío directo a las acciones realizadas por los ingleses, los amotinados devolvieron el poder al emperador anterior, luego de lo cual se lanzaron a tomar otras ciudades.
Acto seguido, se sumaron a la revuelta no sólo más soldados cipayos, sino también gran cantidad de sectores sociales de la India, desde príncipes hasta campesinos, así como gentes de todos las castas y credos (hindúes, musulmantes y sikhs) por igual (Mishra 65). Con esto, la rebelión asumió la forma de una reivindicación localista y anticolonial al mismo tiempo.

Sin embargo, el movimiento habría de fracasar principalmente debido a su falta de coordinación interna y de un proyecto político concreto. Poco a poco, la Compañía fue retomando las ciudades capturadas por los cipayos con la ayuda de los que no se habían sumado a la revuelta, y el movimiento acabó siendo aplastado totalmente en 1858.

Así, es posible afirmar que la rebelión de los cipayos fue una revuelta premoderna, lo cual se evidencia en que fue detonada en el corto plazo por una reivindicación esencialmente religiosa. Además, fue un estallido de cólera de los militares, que luego aglutinó la de los demás sectores de la sociedad india, afectados por el colonialismo. En otras palabras, asumió la forma de una revuelta campesina-urbana anticolonial, pero inspirada por valores propios de una sociedad premoderna. Este tipo de revueltas, como ha sido estudiado, solían producirse cuando los sectores afectados por una situación colonial no aguantaban más y daban rienda suelta a su cólera, pero volviendo luego al estado de cosas el cual no atinaban a transformar por falta de un proyecto concreto (Martínez Peláez 47-51), de manera muy similar a las "jacqueries" medievales europeas.

Por esta misma razón, no hubo en el movimiento cipayo un programa político-ideológico de independencia y 
construcción de una nación para liberar al país, ni tampoco políticas concretas de justicia social o desarrollo incluyente. Más bien, el movimiento se dirigió a recuperar el orden anterior y devolver a los antiguos príncipes al poder, restaurando así el orden de castas y religiones que estructuraba a la sociedad india desde tiempos muy antiguos. Por lo mismo, el movimiento cipayo no llegó a convertirse en una guerra de independencia porque cada sector tenía sus propias reivindicaciones, sin que existiera en ellos un sentido general de liberar la India del colonialismo (Mishra 65).

En el aspecto global, sin embargo, esta rebelión tuvo efectos significativos. El primero de ellos, sin duda alguna, fue que cambió la faz del imperialismo británico en la India y sus políticas globales. Como resultado de ella, la corona británica disolvió la Compañía y asumió directamente el control del subcontinente a partir de un virreinato, dictó leyes para que la cultura india no fuese irrespetada en lo sucesivo, y redujo el número de soldados indios en el ejército y dejó sólo a los que se habían jurado leales a Gran Bretaña. Con ello, la corona inglesa dejó de lado su política de occidentalización y cristianización con tal de asegurar el control económico y del ejército. En suma, si bien la revuelta no logró acabar de llano con el colonialismo inglés en la India, sí modificó seriamente su cariz y lo obligó a reinventarse drásticamente $\mathrm{y}$, sobre todo, a suavizar sustancialmente sus políticas eurocéntricas de aculturación y agresión contra la cultura local. Por ello, podemos afirmar que, pese a todo, la rebelión cipaya sí tuvo repercusiones liberadoras y globales.

\section{V.}

Pasamos ahora al estudio del segundo tipo de revueltas que hemos planteado: las revueltas sostenidas premodernas, pero con tendencias hacia la modernización.

\section{La rebelión de Taiping, China 1851- 1866}

Para comenzar con el primero de los casos, no cabe duda de que la rebelión de Taiping fue causada, como las demás, por la agresión política y económica imperialista. A esto se sumaron las acciones opresivas del gobierno imperial y de la aristocracia señorial de los campos, y el clima de crisis interna reinante en todos los órdenes de la sociedad china de la época, situaciones que acarrearon una fuerte explosión social.

En efecto, después de la I Guerra del Opio (1839-42), los tratados de paz firmados por China con las potencias europeas hicieron que la producción china de textiles se quedara en los puertos debido a la invasión de mercancías manufacturadas inglesas y de otros países europeos (Bai 393). De esta manera, al igual que había venido sucediendo en la India, la industria textilera china fue arrasada por el auge de la producción industrial europea.

Al mismo tiempo, la adicción al opio -promovida por los ingleses- tuvo un aumento exponencial y la economía china se vio afectada por una ingente "hemorragia de plata", pues las reservas del país se vieron orientadas a la compra de mercancías importadas. Además, el gobierno de la dinastía Qing aumentó los impuestos para pagar la guerra, desmejorando con ello las condiciones de vida de los sectores 
populares. A esto se sumó un proceso de concentración de tierras ocurrido en el campo, donde los terratenientes empezaron a arrebatar la tierra a los campesinos y a dejarlos sin medios de producir. Todo esto condujo a severas hambrunas que devastaron a la población campesina. Ante tal clima de sufrimiento humano generalizado de la población china, el estallido de numerosas rebeliones no se hizo esperar.

Así, podemos afirmar que el clima social del país con posterioridad a la I Guerra del Opio era de crisis interna, confrontación social y rechazo popular hacia la reinante Dinastía Qing (Tao 28-29).

En este estado de cosas, la rebelión de Taiping presentó características de revuelta campesina premoderna. Su líder fue un personaje religioso, sus postulados eran esencialmente religiosos y su organización también. Sin embargo, de manera contrastante, en ella se mezclaron estos elementos con reivindicaciones más bien modernas, como la justicia social y el nacionalismo antimperialista, aunque estas no llegan a predominar. Por lo tanto, al igual que en la India, esta rebelión asumió la actitud de los campesinos de épocas premodernas, que se rebelaban pero no actuaban significativamente para cambiar el orden social como un todo, sino que sólo aspiraban a cambiar la dinastía vigente por una que fuera más benevolente con ellos y terminara con los males traídos por la dinastía anterior. Por ello, creencias religiosas sincréticas se mezclaron en sus postulados con propuestas de reformas sociales, y la organización política y militar moderna que asumieron se mezcló con simbolismos procedentes de la mentalidad tradicional. La revuelta se dirigió contra los señores terratenientes y sus in- justicias, pero la manera de canalizar la ira social fue esencialmente premoderna: religiosa -no ideológica- restauradora del orden y no creadora de un orden nuevo. Hubo también acciones de avanzada en cuanto al género y se puso en marcha una política internacional nacionalista, pero sus líderes asumieron el mismo ceremonial de jerarquía, lujo y extravagancia característicos del régimen imperial. En suma, la rebelión de Taiping no modificó sustancialmente el ideario heredado de las épocas imperiales. Esto se hizo visible en sus constantes alusiones a "lo celestial”, que venían, sin embargo, entremezcladas con políticas redistributivas y de reforma agraria. Todo esto explica su incapacidad para llevar a la práctica sus propuestas de cambio social.

El caso fue que hacia 1851 las rebeliones sociales que se habían desatado a raíz de la crisis traída por la Guerra del Opio se fueron aglutinando poco a poco en una sola: la gran rebelión de Taiping. Esta rebelión fue liderada en un principio por Hong Xiuquan, un intelectual rural y maestro de escuela que empezó a simpatizar con la miseria de la gente y asumió una postura localista prochina al deplorar la derrota del país en la Guerra del Opio, por la cual vio a los gobernantes chinos como responsables.

En 1843, Hong leyó cierto libro cristiano -que interpretó a su manera-, y a raíz de esta lectura comenzó a afirmar haber recibido un mandato del cielo para salvar el mundo (Bai 394). Como resultado, se dedicó también a elaborar sus propias doctrinas, que asumieron la forma de un sincretismo entre creencias chinas y cristianas. Por ejemplo, enseñó a adorar a un solo Dios y organizó a sus seguidores en una 
"Asociación para la adoración de Dios." Con esto, el movimiento de Taiping rechazó el confucianismo -legitimador de las jerarquías señoriales de la sociedad china desde hacía milenios- y asumió algunas facetas del cristianismo (Tao 30), religión que, al parecer, estimaba como potencialmente liberadora.

Como resultado, Hong envió gente a propagar su credo en otras regiones -a manera de misioneros-. Con todo -y de manera mucho más moderna- Hong Xiuquan escribió varios libros donde demandaba la igualdad social y se oponía a todo tipo de opresión política. Sin embargo, en su elaboración ideológica, lo religioso no cesaba de confundirse con lo moderno, cosa que era visible, por ejemplo, en que predicaba la hermandad y la igualdad de los seres humanos, pero llamaba "demonios" de su sociedad a todo lo que en su tiempo se oponía a esto, a saber: el imperio, los oficiales y los terratenientes, e instaba a sus seguidores a luchar contra ellos para crear un mundo mejor.

Hacia 1847, los seguidores del movimiento -que empezaban a multiplicarse- iniciaron la lucha armada, y para 1850, el movimiento se propagaba ya por toda China. Esto llevó a que, en 1851, Hong Xiuquan organizara definitivamente el ejército de Taiping, con lo que el líder empezó a llamar a su organización "el reino celestial de Taiping" (de Tai: "gran" y Ping: "paz") y se autonombró su "rey celestial". Además, estableció todo un sistema político y militar y empezó a ganar más regiones, en donde nombró a otros príncipes y autoridades.

En esta etapa, el movimiento ganó mucho terreno debido a que al principio ni la dinastía Qing ni los británicos le prestaron atención dado que estaban negociando los tratados de la guerra (Tao 30).

Entretanto, el ejército de Taiping avanzaba matando oficiales Qing, nobles y terratenientes a su paso. Además, los alzados quemaban documentos de propiedad y de deudas y distribuían granos, dinero y bienes a los campesinos pobres (Bai 395). Así, poco a poco, los alzados fueron tomando más y más ciudades y convirtieron Nanjin en su capital, cambiándole el nombre a Tianjing, es decir, "capital celestial."

Pero la revuelta no se limitó únicamente a la expansión territorial: un impetuoso programa de reformas sociales fue llevado a cabo. Por ejemplo, los rebeldes establecieron el "sistema celestial de tierras" y crearon comunidades agrarias igualitarias, gobernadas por oficiales del pueblo como poder primario. Del mismo modo, los excedentes se daban al gobierno Taiping para ser redistribuidos y para pagar por otras necesidades de los campesinos. En suma, las medidas tomadas asumieron un fuerte tinte igualizante, antiseñorial y modernizador.

Con todo, tales medidas en realidad no llegaron a ponerse en práctica totalmente pero, hasta donde lo fueron, sí lograron mejorar visiblemente las condiciones de vida de los campesinos, quienes en adelante tuvieron tierras y dejaron de pagar deudas e impuestos a los terratenientes (Bai 396).

También, la revuelta de Taiping proveyó medidas a favor de la mujer, tales como darles tierras, eliminar la esclavitud femenina y la prostitución, formar un ejército femenino y dar a esta población participación en el gobierno. En el plano internacional, el reino de Taiping desconoció los opresivos tratados impuestos a China por los ingleses y prohibió la venta de opio. 
En este estado de cosas, hacia 1856 la rebelión había logrado el máximo de su expansión -a pesar de haber tenido varias derrotas- $\mathrm{y}$, como resultado, más movimientos comenzaron a estallar inspirados por ella (Bai 397-398).

Sin embargo, al poco tiempo, el movimiento empezó a corroerse internamente por varias razones que entraron en contradicción con sus objetivos sociales. Estas fueron esencialmente las causas de su derrota y estuvieron ligadas a su asunción de simbolismos sociales premodernos, que no lograron deslindar de sus reivindicaciones sociales modernizantes. En primer lugar, el complicado sistema de rangos para los mandos del movimiento implantado por Hong Xiuquan parecía ir en contra de su propia prédica de igualdad (Bai 403-4). También, los rebeldes de Taiping implantaron ceremonias demasiado rígidas de jerarquía, y los líderes sucumbieron a la tentación de asumir un estilo de vida marcado por el lujo y la extravagancia. Finalmente, el orden jerárquico implantado hizo que surgieran faccionalismos y luchas de poder a lo interno del movimiento. En otras palabras, los rebeldes de Taiping pusieron en práctica un orden muy similar al de la corte imperial china, a la que parecían querer imitar. Ante el caos generado por estos problemas, saboteadores enviados por el gobierno imperial se infiltraron fácilmente para minar el movimiento (Bai 404).

Como resultado, en 1856, en la cumbre de su poder, los líderes del reino celestial de Taiping iniciaron una sangrienta lucha interna, en la que fueron asesinados muchos de ellos. En 1859, pese a todo, los rebeldes lograron superar la crisis y los nuevos líderes continuaron con su política de promo- ver medidas modernizantes. Sin embargo, una vez más y como había ocurrido anteriormente, no logran llevar estas medidas a la práctica.

Tales convulsiones internas dieron la oportunidad a la Dinastía Qing de contratacar y en 1860 el imperio chino concertó una alianza con las fuerzas británicas, francesas, estadounidenses y rusas para destruir el movimiento. A raíz de ello, grandes enfrentamientos se produjeron, hasta que en 1864 las fuerzas combinadas del gobierno imperial y las potencias extranjeras lograron derrotar a los rebeldes (Bai 406-7). ${ }^{2}$

Pese a todo, la rebelión de Taiping tuvo a su haber numerosos éxitos. En primer lugar, amenazó seriamente con derrocar a la dinastía Qing. También, se sostuvo por casi 20 años (1850-69), llevó la guerra por 16 provincias de China, conquistó 600 castillos y fue considerada la guerra civil más grande del mundo en su época (Tao 28-30).

Sin embargo, no planteó un proyecto político claro que fuera más allá de eliminar al emperador vigente y sustituirlo por una nueva dinastía formada por sus líderes, que se situaron en las coordenadas de la cultura política china más tradicional.

De hecho, basándose en fuentes periodísticas, el historiador chino Jiang Tao ha afirmado que los rebeldes de Taiping en realidad tuvieron características similares a las de otras típicas revueltas campesinas anteriores, con la sola diferencia de que su movimiento fue mucho más grande que cualquiera de sus predecesores. Esto lo lleva a afirmar que el reino celestial de Taiping fue la última revuelta campesina de la historia premoderna de China, pero la más grande y poderosa (Tao 30-1), que estableció un sistema político y militar, 
y confrontó a la clase terrateniente y al ejército de una manera inédita, pero fracasó por tener una revindicación esencialmente premoderna, en vez de un proyecto revolucionario ideológico con un programa de transformación social.

Sin embargo, no cabe duda de que, en lo interno, pese a que la rebelión de Taiping fue derrotada, sí consiguó impulsar una atmósfera propicia para más cambios revolucionarios en el futuro en la sociedad china (Bai 406-7).

Por lo que se refiere a su proyección global, la rebelión de Taiping tuvo influencia en pensadores y en revoluciones de otras latitudes, por ejemplo, a partir de su denuncia internacional de los imperialismos. Además, en la época fue claro incluso para pensadores europeos como Karl Marx que todo había sido causado por la Guerra del Opio y por la invasión británica, pues con ellas China fue abierta violentamente al contacto con el mundo industrializado europeo (Tao 28-29). Incluso ha sido documentado que Marx creyó que la revuelta iba a generar una revolución en Europa.

Así, al igual que el movimiento indio de los cipayos, la rebelión de Taiping logró poner un freno a los imperios globales, a los que se opuso exitosamente -por lo menos por un cierto lapso de tiempo-, frenó su expansión y limitó sus posibilidades de acción, al menos en el ámbito chino (Tao 30-1).

\section{La Rebelión de Dong-Hak, Corea, 1894}

Otra rebelión social que estuvo ligada al avance imperial europeo en el continente asiático, a las conflictividades internas de las sociedades del Asia Oriental herededadas de siglos atrás, y a los clamores en pro de la moderni- zación que ambas suscitaron en importantes sectores sociales de la región, es la rebelión de Dong-Hak (o Tonghak) de Corea. Con el avance imperialista, Corea se desestabilizó internamente y se detonaron movimientos sociales que también llevarían a una entrada inconsciente en la modernidad (Hwang 119). En este caso, la diferencia estriba en que la revuelta no fue causada tanto por la invasión de potencias occidentales, sino por la invasión de Japón y principalmente por problemas internos, especialmente por la acumulación de tensiones y descontentos sociales, y también debido a conflictos religiosos entre la religiosidad tradicional coreana y el ingente avance del catolicismo en el país. Estos factores llevaron a que se produjese un sinnúmero de revueltas campesinas desde fines del siglo XVIII. De estas, la más significativa como causa del movimiento por estudiar, fue la que se produjo en 1862.

$\mathrm{Al}$ igual que sucedió en la rebelión china de Taiping, en este movimiento se pueden ver características premodernas. Principalmente, es visible la existencia de líderes religiosos de carácter profético que incitan a la revuelta contra las iniquidades de su sociedad, pero desde una prédica esencialmente religiosa, con bases sincréticas.

En 1862, a raíz de la revuelta ocurrida ese año y como reacción contra toda la seguidilla de rebeliones campesinas acaecidas desde inicios del siglo contra las extorsiones que los funcionarios locales corruptos y la corte le hacían al campesinado, un predicador ambulante llamado Ch'oe Cheu empezó a enseñar unas nuevas doctrinas de su propia creación (Hwang 121).

$\mathrm{Al}$ igual que sucedió con Hong Xiuquan en la China de Taiping, Ch'oe 
Cheu entremezcló reivindicaciones modernizantes -que podrían pensarse originadas en el pensamiento occidental-, con elementos autóctonos, llamando a la revuelta y buscando reivindicar la identidad cultural coreana frente al avance extranjero. En sus prédicas, Ch'oe Cheu entremezcló elementos católicos como la creencia en un Dios único y personal y en la hermandad e igualdad de los seres humanos, con elementos confucianos, taoístas y hasta shamánicos y nativistas propios de la espiritualidad coreana, tales como ciertos rezos, encantamientos y métodos de curación y adivinación (Hwang 122). Con esto, sin duda su objetivo era llevar a cabo una simbiosis entre las prácticas religiosas establecidas y la religiosidad popular, sumándoles algunos elementos de la espiritualidad cristiana, con lo que el movimiento adquirió un fuerte tinte de rescate, pero también de renovación de la identidad cultural coreana. De hecho, el nombre Dong-Hak significa "enseñanza coreana" o "enseñanza del este" siendo el concepto de "este" equivalente al de "Corea", como opuesto a lo que sería la "enseñanza del oeste", es decir, el catolicismo occidental.

Claro está que estas prédicas no podían pasar inadvertidas para las esferas del poder pues, enseñando tales cosas, Ch'oe Cheu difundía elementos que, desde la corte coreana de Joseon, eran percibidos como heterodoxos y subversivos. Para comprender esto hay que recordar que las autoridades de Joseon desconfiaban del catolicismo por su prédica de igualdad de los seres humanos como hijos de Dios (Hwang 122), ya que esto ponía en peligro el orden jerárquico confuciano. Esto había llevado a la dinastía en el poder a lanzar varias persecuciones contra los conversos en el siglo XIX. Por estas situaciones, el movimiento de Dong-Hak fue inmediatamente mal visto.

Como resultado, en 1864, Ch'oe Cheu fue arrestado y ejecutado (Hwang 121). Sin embargo, sin darse cuenta, lejos de acabar con él, lo que las autoridades lograron fue convertirlo en un mártir, y sus seguidores continuaron practicando sus creencias de manera clandestina por 30 años, hasta la revuelta de 1894 (Hwang 122).

Otro asunto que estaba en el trasfondo de las prédicas y críticas sociales de Ch'oe Cheu y sus seguidores era la agresión imperial, que también resultaba ser un motivo de preocupación y un factor de desestabilización de la ya de por sí precaria estabilidad social de la sociedad coreana. Desde 1866, barcos europeos y estadounidenses habían venido invadiendo las costas de Corea para establecer bases de comercio forzado, ejerciendo así dinámicas imperialistas sobre ella (Hwang 124). Además, en 1876 se firmó con Japón el tratado de Kanghwa que abrió Corea a un comercio desigual con condiciones netamente favorables a su vecino japonés, que ya estaba en proceso de convertirse en potencia imperialista (Hwang 123).

En este contexto, al igual que estaba sucediendo en Japón y China, sectores de la sociedad coreana empezaron a abogar por una apertura del país a aprender del exterior y por ello, el gobierno coreano empezó a mandar misiones a China y Japón para aprender de sus procesos de modernización en el campo del Estado y la tecnología (Hwang 125-128). De esta forma, el Estado coreano empezó a hacer reformas modernizantes hacia la década de 1880. 
Sin embargo, esto también trajo consecuencias negativas y desestabilizadoras para la sociedad coreana. La apertura comercial impulsada por el régimen de Joseon, por ejemplo, hizo que se exportaran grandes cantidades de arroz, por lo que el precio del grano subió para los campesinos y muchos perdieron sus tierras. También, los funcionarios los explotaban especulando con las diferencias de precios cuando estos fluctuaban (Asociation of Korean History Teachers 212).

Así, impulsada por estos factores, la revuelta empezó en áreas rurales, con campesinos armados con lanzas de bambú que se enfrentaron y derrotaron a las tropas gubernamentales (Yim 44). Luego, el motín se fue difundiendo por todo el país (Hwang 131).

En lo global, el principal factor causante del conflicto de Dong-Hak fue el enfrentamiento entre China y Japón, que se hallaban en plena rivalidad por dominar la península coreana (Hwang 129-30). En este caso, entonces, el factor global detonante tuvo que ver, no tanto con la invasión de potencias imperialistas occidentales, sino con la de potencias asiáticas que pretendieron hacerse con el control del país.

De hecho, la revuelta de Dong-Hak estalló precisamente en coincidencia con un momento álgido de la historia coreana en que los japoneses invadieron el país, depusieron el gobierno de Joseon y lo sustituyeron por facciones dinásticas serviles a ellos, a las que forzaron a imponer reformas convenientes a sus intereses. El conflicto entre imperios se produjo debido a que los depuestos gobernantes habían pedido la ayuda del ejército chino para aplastar a los rebeldes de Dong-Hak, por lo que los japoneses también obtuvie- ron de sus esbirros coreanos el apoyo para expulsar al ejército invasor chino (Hwang 129-30). Incluso, en el transcurso de la revuelta hubo batallas de los alzados con el ejército chino-coreano (Hwang 131). Estos enfrentamientos habrían de desembocar en la Guerra Chino-Japonesa de 1894.

Los amotinados de Dong-Hak se rebelaban de hecho contra varios actos. En primer lugar, contra la venalidad en los cargos y las extorsiones de los funcionarios locales hacia los campesinos, pero también contra el deterioro económico y el dominio comercial externo, especialmente por parte de Japón (Hwang 130). Además, la rebelión lanzaba serias críticas contra las excesivas jerarquías sociales señoriales y aristocráticas de la sociedad coreana, así como contra la corrupción y decadencia del gobierno, y pedían redistribuir la tierra. Por todos estos factores, el movimiento adquirió definitivos tintes modernizantes (Hwang 131).

También -y en esto se asemejan al movimiento chino de Taiping- los rebeldes de Dong-Hak plantearon otros tipos de reivindicaciones modernas, en este caso de género, tales como la igualdad de hombres y mujeres (Bae 11). También, además de llegar a una igualdad entre géneros, plantearon abolir las clases sociales, por lo que llegaron a ideales modernos por su rechazo a la sociedad patriarcal y señorial, cosa que los llevó a asemejarse a los movimientos socialistas de Occidente (Yim 42-43). Así, la rebelión de DongHak apuntó claramente a desintegrar el viejo orden social y a moverse hacia la modernización. ${ }^{3}$

De esta forma, la revuelta reivindicó un mundo utópico y una dignidad humana opuestos a las jerarquías del 
confucianismo y a la relación amo/siervo de la sociedad señorial coreana (Yim 40). Esto fue así debido a su planteamiento -de raíces cristianas- de que los seres humanos son iguales, pues en el cristianismo el ser humano es igual a Dios. Por ello, desde su pensamiento teológico, los alzados afirmaban que el ser humano debía ser servido como un Dios y -en consecuencia- la sociedad se debía estructurar como una comunidad de caballeros, no como un orden de señores y siervos. Por estas razones se puede decir que este movimiento impulsó la conciencia nacional, pero ciertamente también la conciencia individual, ambas eran muy atractivas para el empobrecido pueblo coreano (Yim 41).

Al principio, el gobierno de Joseon negociaba con los rebeldes y pedía a los chinos y japoneses salir de Corea, esto calmó la revuelta. Pero al ser este gobierno depuesto por los japoneses -quienes buscaban lograr ventajas comerciales para su país-, el nuevo gobierno títere optó por la solución armada. Los japoneses tomaron el palacio real de Seúl y atacaron a las fuerzas chinas (Asociation of Korean History Teachers 215), y lanzaron también la represión armada contra la revuelta.

Como resultado, en el otoño de 1894, la rebelión se activó de nuevo para oponerse al nuevo gobierno projaponés y a la invasión. Empero, los rebeldes fueron finalmente aplastados por las fuerzas combinadas coreano-japonesas. El nuevo gobierno inició, sin embargo, reformas modernizantes bajo el influjo y a imitación de Japón (Asociation of Korean History Teachers 216).

De esta forma, podemos concluir que la invasión japonesa trajo como resultado un agravamiento de los conflictos sociales que ya existían en la socie- dad coreana, especialmente de aquellos concernientes a la situación del campesinado bajo el sistema aristocrático, lo cual impulsó la revuelta (Yim 43).

Así, la revuelta de Dong-Hak fue antiseñorial, pero también contraria a la agresión imperialista y tuvo una orientación reformista/modernizadora impulsada desde abajo. Además, puso en marcha una ideología nacional iniciada durante la desintegración de la sociedad premoderna de Joseon, que impulsó el proceso de modernización (Bae 4).

En cuanto a sus implicaciones globales, sin duda alguna fue fundamental su papel como detonante de la Guerra Chino-japonesa, la cual a su vez gatilló la rebelión de los boxers de China.

\section{La rebelión de los Boxers, China, 1899-1900}

El movimiento chino de los boxers fue producto de la partición de China después de la Guerra Chino-Japonesa -detonada en buena medida por el enfrentamiento entre China y Japón por dominar Corea durante el alzamiento de Dong-Hak-, y también de la ingente cantidad de agresiones externas lanzadas contra China en este período. A todo esto se sumó el desastre nacional producido por la imposibilidad que mostró el régimen imperial para modernizarse y modernizar el país, la larga cola de revueltas sociales anteriores, así como la conflictividad religiosa y cultural causada por el avance de las iglesias católicas en China (Bai 435).

En cuanto al desarrollo mismo del movimiento, resulta interesante señalar, como similitud con el alzamiento coreano de Dong-Hak, que los boxers en realidad ya existían como tales desde mucho tiempo antes, pero 
no iniciaron su revuelta sino hasta el año 1899 (Bai 434).

Socialmente hablando, el movimiento estaba compuesto principalmente por campesinos -muchos de ellos jóvenes rurales empobrecidos- (Bai 434), pero también se unieron nobles y terratenientes conservadores motivados por su rechazo a la presencia extranjera y a las innovaciones modernas en la sociedad china. Esto dio al movimiento un semblante sumamente complejo. Juntos, todos estos sectores asumieron el nombre guerrero de YiHe-Tuan, es decir, "milicia unida en la rectitud" (Lee 73 ).

Además, otro elemento que añadió complejidad al movimiento fue que, contrariamente a todos los otros, tuvo apoyo gubernamental pues la dinastía Qing se alió con ellos y les reconoció estatus legal. Esto se debió principalmente a que la emperatriz $\mathrm{Ci} \mathrm{Xi}$ quería valerse de ellos para destronar a Guang Xu, su predecesor en el trono, y así asumir el trono del imperio.

Así las cosas, el movimiento boxer se originó y difundió principalmente por el norte de China (Lee 73), región donde, desde mucho tiempo atrás, había abundantes sectas y sociedades secretas rebeldes contra la dinastía Qing (Lee 80). Además, esta región era azotada por una verdadera cultura de la violencia producto principalmente de los grupos de bandidos que hostigaban a los campesinos y de las luchas entre aldeas por controlar los recursos naturales. Esto con frecuencia conducía a hambrunas, lo que se veía agravado si además se producían desastres naturales. Ante este panorama, las sectas locales y las iglesias cristianas eran abrazadas por los campesinos, pues les ofrecían protección contra la violencia, aunque con frecuencia los grupos de creencias conflictuaban también entre sí (Lee 87).

De esta manera, podemos ver que el movimiento de los boxers presentó características muy parecidas a los otros movimientos analizados en este apartado. Al igual que las rebeliones de Taiping y Dong-Hak, los boxers manejaron elementos religiosos de corte sincrético, lo que evidencia las influencias de las potencias modernas en el movimiento, aunque este también tomó sus creencias y rituales de varios grupos secretos y rebeldes del norte de China que se unieron para formarlo (Lee 78). A eso se sumaron elementos religiosos folklóricos de la región -lo que recuerda mucho a Dong-Hak-, así como de las asociaciones de practicantes de artes marciales (boxers) (Lee 73). Por ejemplo, los boxers creían volverse inmortales e invulnerables por medio de rituales de posesión espiritual. Estas ideas se hicieron evidentes cuando atacaron a chinos cristianos y misioneros (Lee 87), lo que muestra el choque religioso que manejaban contra el cristianismo, cosa que, en este caso, los diferencia de Dong-Hak y Taiping.

Como hemos dicho, los boxers principaron su revuelta en 1899. Pronto empezaron a lograr grandes victorias contra los ejércitos Qing y se extendieron rápidamente (Bai 434). Al poco tiempo, entraron en Pekín, donde quemaron iglesias, atacaron extranjeros y asumieron porciones del gobierno. Fue entonces cuando la dinastía Qing les dio su reconocimiento (Bai 437). Como resultado, cantidad de nuevas revueltas empezaron a producirse en el resto de China.

Como resultado, preocupadas por la posible caída de la dinastía Qing y por el consecuente ascenso al poder de unos rebeldes declaradamente hostiles 
a Occidente, las potencias imperialistas europeas lanzaron un ataque coordinado contra China (Lee 73). Los occidentales se unieron entonces para destruir el movimiento en una óctuple alianza que incluía Inglaterra, Rusia, Japón, Estados Unidos, Alemania, Francia, Italia y Austria, que enviaron un ejército conjunto en 1900 y lanzaron varios ataques (Bai 436).

Ante estas hostilidades, la dinastía Qing declaró la guerra a los extranjeros (Bai 437). Sin embargo, en una conjuración de la reina Dowager $\mathrm{Ci} \mathrm{Xi}$, las autoridades chinas en realidad estaban negociando con los invasores y complotando contra los rebeldes, con el fin de destronar al anterior emperador y colocarla a ella en el trono imperial. Como táctica, las autoridades conspiradoras se las arreglaron para colocar oficiales Qing al mando de las milicias boxers, con el fin manipularlas para lograr sus fines.

Con todo, tras una serie de ataques de los europeos que culminaron con la toma de la capital, el gobierno Qing se vio obligado a huir a Xi'an. Finalmente, la emperatriz $\mathrm{Ci} \mathrm{Xi}$ acabó por entregar la capital a los extranjeros los cuales tomaron además otras ciudades donde cometieron atrocidades. Habiendo negociado así con los occidentales, la emperatriz ordenó a sus oficiales en la capital acabar con los miembros restantes del movimiento Yi He Tuan (Bai 437).

En este contexto, los ejércitos occidentales competían entre sí por apoderarse de más porciones de China, pero luego los Estados Unidos lograron ponerlos de acuerdo para devolver el poder a Ci Xi y mantener la integridad territorial de China, controlándola como un codominio (Bai 438). Con esto, un tratado despótico fue impuesto a China, el cual daba grandes derechos a las potencias occidentales, que incluían la posibilidad de estacionar tropas en el país. El tratado fue aceptado por $\mathrm{Ci} \mathrm{Xi}$ pues le garantizaba su continuación en el poder.

Así, en lo esencial, el movimiento boxer mostró características muy similiares a los otros de su mismo tipo. Indudablemente, los boxers fueron otro movimiento nativista, identitario, religioso y sociopolítico, que planteó reivindicaciones sociales y principalmente políticas, muchas de ellas de tono modernizante, pero que no logró realizarlas adecuadamente por carecer de un proyecto político-ideológico claro y permanecer anclado en moldes premodernos de acción y pensamiento.

Sin embargo, es evidente que tuvo implicaciones globales de gran trascendencia, pues no cabe duda de que el movimiento boxer fue un episodio más de la resistencia de diversos pueblos -en particular de los asiáticos- contra los poderes globales de este tiempo, muy concretamente aunque no únicamente, contra el imperio-mundo inglés, (Lee 86). Además, el alzamiento logró influenciar radicalmente a este imperio pues, aunque el levantamiento fue exterminado, este logró frustrar el desmembramiento de China (Bai 437). Además, el alzamiento boxer también obligó a la potencia inglesa a dejar de lado su política de aislamiento y a buscar aliarse con otras potencias imperialistas para combatirlo, por lo que representó un momento de transición en la política británica (Lee 87). También, el movimiento obligó a Japón a despachar tropas contra él (Lee 88). Para terminar, cabe señalar que el movimiento de los boxers también tuvo implicaciones globales en el sentido de que se ha dicho que influenció 
la revuelta de Dong-Hak de Corea, así como a los nacionalistas indios posteriores a la rebelión cipaya (Lee 88).

\section{VI.}

Como mencionamos atrás, el tercer tipo de revueltas está constituido específicamente por el incidente Chichibu de Japón, el cual, en contraste con los movimientos de los otros países asiáticos que analizamos, más bien fue el resultado del rechazo y resistencia a la acelerada modernización capitalista que sufrió el país como producto de las reformas del período Meiji. Por ello, representa una ruptura respecto a los movimientos campesinos y urbanos del período Edo, que más bien se asemejan a sus homólogos europeos y asiáticos de la Edad Media (Tsutomu, 16-17).

\section{El incidente de Chichibu, Japón, 1884}

Para situar este movimiento social en su adecuada perspectiva, es necesario entender que, a diferencia de los otros países que tratamos, Japón había emprendido un extenso programa de modernización a partir de 1842. La puesta a punto de este programa de reformas fue el resultado de la llegada al país de noticias sobre la derrota china en la I Guerra del Opio (Tanaka 168). Por ello, a la vista de lo que estaba sucediendo en su vecindad, las elites japonesas empezaron a plantearse seriamente la necesidad de adaptar su país a los requerimientos de la modernidad europea, pues resultó claro para ellos que la derrota china ante los ingleses había sido producto de la incapacidad del régimen imperial chino -agrario y señorial- de hacer frente a la modernidad británica, dotada de un Estado Moderno fuerte y funcional, de una visión racionalizada del mundo y, especialmente, de una ciencia y una tecnología asociadas a la economía industrial y, por supuesto, a las armas.

Además de lo anterior, mientras las elites japonesas discutían estos asuntos, un acontecimiento concreto se produjo y empujó aún más a la sociedad japonesa a optar voluntariamente por la modernización. Este hecho fue la apertura forzosa de Japón al comercio mundial provocada por la llegada del Comodoro Mathew Perry en 1853 -quien volvió luego en 1854 con "sus naves negras" (acorazados construidos en metal a diferencia de los antiguos barcos de madera conocidos hasta la fecha)-, amenazando con cañonear las ciudades portuarias japonesas si el país no revertía su antigua política de cerrarse al comercio con los extranjeros, adoptada desde el siglo XVII.

Japón inicia entonces un proceso de transformación integral signado por una adopción prácticamente imitativa de todos los parámetros de funcionamiento de la modernidad occidental, lo cual, sin embargo, nunca riñó sino antes bien se adaptó perfectamente a las viejas estructuras de la cultura japonesa, generando así un proceso que ha sido denominado de "modernidad equilibrada" (Le Goff 84).

De esta forma, la razón por la que existen diferencias importantes de los movimientos sociales japoneses de este período respecto a aquellos acaecidos en los otros países asiáticos que analizamos, estriba en que, en contraste con ellos, en Japón sí se lleva a cabo un proceso de modernización que, pese a resultar ser, en principio, armonioso 
con la cultura local, generó importantes fracturas y fuentes de conflicto en la sociedad japonesa, pues implicó un arrasamiento de las viejas estructuras que conformaban el modo de vida campesino (premoderno). Por lo tanto, al igual que en muchas revueltas campesinas europeas del tiempo de la Revolución Industrial, este movimiento fue más bien antimoderno y anticapitalista, pues buscó proteger viejas leyes y costumbres frente al avance modernizador, especialmente porque con él los campesinos perdían sus tierras (Bae 4). ${ }^{4}$

Efectivamente, las reformas modernizantes de Meiji agravaron los problemas económicos que los sectores populares japoneses habían vivido desde siempre en períodos anteriores, pero que ahora se volvían más acuciantes debido a las presiones que se ejercían sobre ellos por las prisas renovadoras de las elites dirigentes. En este contexto, las deudas de los sectores bajos urbanos y campesinos fueron el punto de mayor tensión.

Como resultado, el 1 de noviembre de 1884, campesinos del norte de Tokyo y del distrito de Chichibu, azotados por la pobreza debido al aumento de impuestos y de las deudas a altas tasas de interés impuestas a los pobres por prestamistas inescrupulosos, se levantaron en armas exigiendo prórrogas para el pago. Los alzados atacaron a prestamistas y oficiales de gobierno en varias localidades y entraron en combate con la policía civil y militar (Tsutomu 17) y realizaron posteriormente importantes avances militares en varios condados aledaños (Tsutomu 19-21).

En su lucha, los rebeldes de Chichibu asumieron reivindicaciones $\mathrm{y}$ formas de organización que podrían entenderse como típicamente modernas.
Por ejemplo, exigían un igualitarismo social con aplicación de políticas redistributivas de la riqueza, reivindicación muy moderna, próxima de la "cuestión social" que se debatía en las democracias occidentales de la época (Tsutomu 21). Además, al poco tiempo de iniciado el alzamiento, los rebeldes se organizaron militarmente como un ejército regular a la manera europea (Tsutomu 18).

Sin embargo, pese a estos aparentes visos de modernidad, los revoltosos también reprodujeron simbolismos y formas de conducta heredados del período feudal japonés y, por ejemplo, sus jefes se empezaron a presentar ante los demás como guerreros (aunque no tenían ninguna experiencia militar) utilizando, entre otras cosas, las armas y vestimentas que eran hasta entonces propias exclusivamente de los guerreros samurai -aunque también eran empleadas por los señores terratenientes del campo-. Sin duda, con ello los líderes del movimiento buscaban rodearse de un aura de poderío enraizado en los símbolos de las antiguas tradiciones feudales japonesas, para así proyectar la imagen de que estaban en capacidad a enfrentarse al Japón imperial (Tsutomu 19).

De manera interesante y en coincidencia con esta ambivalencia entre tradición y modernidad que mostraba el movimiento, la sublevación de Chichibu fue entendida por la prensa como una guerra civil, debido al carácter militar de su organización (Tsutomu 1921). Sin embargo, al mismo tiempo, los periódicos japoneses presentaron a sus líderes como un grupo de vagos y embusteros, que habían engañado a una multitud de campesinos ingenuos pero -y esto es lo más significativo- también presentó el incidente como el resultado 
del fanatismo de unos pocos exaltados con una visión de mundo muy tradicionalista y que no lograban adaptarse a la vida moderna.

Finalmente, al igual que en los casos anteriores, la fusión conflictiva entre tradición y modernidad que presentaba el movimiento y su falta de proyecto político-ideológico de cambio fueron los factores que condujeron a su derrota. El 9 de noviembre, los alzados de Chichibu fueron aplastados por un ataque del ejército japonés -este sí organizado como un moderno ejército de línea y situado dentro de un proyecto modernizador concreto- (Tsutomu 1921). Como resultado, los participantes fueron castigados como criminales comunes, asesinos e incendiarios y 7 de ellos fueron sentenciados a muerte. Otros 296 fueron condenados con penas fuertes, 448 con penas menores y 2642 fueron simplemente multados.

Así, el Estado reformista modernizador de Meiji -como todo Estado moderno- no hizo sino imponer su autoridad y ejercer su "monopolio de la violencia legítima" -como díría Max Weber- así como proteger la propiedad privada (en este caso la de los prestamistas) -cosas ambas muy a tono con lo que se espera de un Estado moderno-. Así, reprimieron brutalmente a un conjunto de rebeldes salidos de los sectores populares, que tan sólo pretendían vengarse de unos prestamistas que les imponían onerosas deudas, y exigir del Estado una mayor preocupación por sus necesidades sociales.

En este caso, también a diferencia de los movimientos anteriores, el movimiento de Chichibu careció por completo de efectos sobre la globalidad y fue totalmente incapaz de impedir que siguieran adelante las causas glo- bales que le habían dado origen. Esto fue así porque no se dirigió contra una potencia invasora extranjera cuyo ataque presionara al país hacia una modernización cuya realización no podía sino resultar conflictiva e inacabada -además de reñida con las tradiciones locales- sino que, antes bien, su lucha fue contra un modernismo interno que más bien iba a llevar al país a convertirse en la primera potencia imperialista no europea de su tiempo y que, por lo tanto, no podía tolerar ningún viso de rebelión interna que retrasara o impidiera su avance. La razón de su derrota fue, pues, al igual que en los otros movimientos vistos, su falta de un proyecto político claro, que fuese más allá de su visión premoderna de las cosas.

El gobierno de Japón continuó así con su visión capitalista imperial y con sus reformas modernizantes, empeorando con ello la situación de los campesinos y sectores empobrecidos. Después de la movilización de Chichibu, los movimientos populares acompañados de violencia desaparecieron por completo de la sociedad japonesa (Tsutomu 21) y esta se enrumbó hacia la expansión imperial que llevaría, en último término, a la II Guerra Mundial.

\section{VII.}

A la luz de lo estudiado sobre los movimientos sociales asiáticos de mediados y fines del siglo XIX, podemos afirmar que existe una definitiva influencia histórica de los procesos globales en las luchas sociales, pero sin duda también lo contrario. Además, esta influencia mutua asumió la forma de un claro choque entre modernidad y premodernidad. Así, con la irrupción de 
ambos elementos -el imperialismo y la modernización- se produjo un profundo trastorno en todo el orden milenario del este asiático (Hwang 131).

Como resultado de este choque, en todos los casos, las movilizaciones fueron el resultado de la resistencia de los pueblos asiáticos a las invasiones imperialistas, pero también se produjeron porque, en casi todos los casos, la invasión imperialista hizo estallar conflictos internos muy serios en las sociedades locales, desnudando así sus déficits en todos los órdenes. Así, las sociedades asiáticas fueron sin duda desafiadas por la modernidad europea, que las confrontó con la necesidad de asumirla o ser avasalladas (Ianni 61).

Ante tal desafío, las elites gobernantes en ocasiones lanzaron procesos modernizadores -como en Japón-. Sin embargo, las más de las veces, en realidad, antepusieron sus intereses inmediatos de poder al interés de largo plazo de la modernización del país (como única manera efectiva para resistir el avance imperial) y, más todavía, al interés de enrumbar a sus propios pueblos hacia un desarrollo en términos modernos. La excepción a esto, como hemos dicho, claramente es Japón donde, sin embargo, un proceso de modernización acelerado e inmisericorde fue más bien la causa que empujó a muchos al empobrecimiento y la rebelión.

Así, pese a su falta de ideología y proyecto político claros y a ser poco más que reacciones primitivas y explosiones de desesperación -elementos que los llevaron a ser esencialmente movimientos conservadores, espontáneos y sin proyecto ideológico-, algunas de las movilizaciones estudiadas mezclaron ya su estallido con ideas de modernización. Esta limitación sería superada sólo con la aparición de ideologías políticas que proveyeron a los movimientos de un sentido de dirección y un proyecto verificable de transformación, basado en la crítica al statu quo dominante.

$\mathrm{Y}$ esto nos lleva, como punto final, a otro aspecto fundamental: la efectividad de estos movimientos ¿son un mito? ¿son estos movilizaciones verdaderamente inútiles donde los que padecen son los más débiles y no logran nunca transformar el orden social establecido?

La respuesta a estas preguntas es definitivamente contraria. Si bien todos los movimientos estudiados fueron violentamente aplastados, no cabe duda de que -a excepción del movimiento de Chichibu- todos lograron alterar la política de las potencias. Además, también fueron el fermento que preparó cambios de fondo en sus sociedades, a futuro. Como resultado, fueron definitivamente un componente del proceso de modernización (Ianni 59-74) del mundo asiático, lo detonaron y contribuyeron a él. Así, al contribuir a liquidar las viejas estructuras y modelar las nuevas, en definitiva, la lucha social jugó un papel definitivo en la modificación de las estructuras sociales de su tiempo.

Las anteriores constataciones históricas -motivadas por nuestra muy actual preocupación por los procesos globales- no pueden menos que dejarnos la inquietud de preguntarnos ¿qué papel pueden tener los procesos globales de hoy en el detonar de movimientos sociales? y ¿cómo estos pueden influenciar la transformación social en el contexto de la crisis actual del modelo globalizado? 


\section{Notas}

1 Este trabajo fue presentado como ponencia en el II Simposio Internacional de Estudios sobre China, realizado en la Universidad de Costa Rica del 20 al 21 de noviembre de 2014 y elaborado como artículo en el contexto de la pasantía del autor como profesor invitado en la Universidad de Toulouse Jean Jaurès en enero y febrero de 2015.

2 Con todo, en 1868 todavía había fuerzas Taiping que quedaban luchando

3 De manera interesante, algunos autores han señalado que en el movimiento de Dong-Hak la lucha de los campesinos por la tierra no fue tan preponderante -como lo fue, por ejemplo, en Japón, en la China de Taiping o en la Europa del siglo XVIII y XIX- porque no hubo en Corea un proceso de "acumulación originaria", es decir, de desposesión de la pequeña propiedad rural por parte de los grandes terratenientes, de manera que los alzados no se sentían presionados a reivindicar su derecho a la tierra, como tampoco su "economía moral", compuesta de costumbres y leyes ancestrales (Bae 6).

4 Esto recuerda muy de cerca los movimientos sociales de la Inglaterra de la Revolución Industrial que son analizados por E.P. Thompson, en los que los amotinados defendían sus viejas costumbres medievales, a las que este autor llama "la economía moral de la multitud", frente al avance industrial en Inglaterra.

\section{Bibliografía}

Asociation of Korean History Teachers. A korean history for international readers. Seúl: Humanist Publishing Group Inc., 2010. Impreso.
Bae, Hang-Seob. "Comparative historical study on Donghak peasant war." Peasant movements and anti-invasion campaigns in the transition to the modern period. Seúl: Sung Kyun Kwan University, 2014. Impreso.

Bai, Shouyi. An outline history of China. Pekín: Foreign Language Press, 2010. Impreso.

Hwang, Kyung Moon. A history of Korea. New York: Palgrave-Macmillan, 2010. Impreso.

Ianni, Octavio. "La occidentalización del mundo." Teorías de la Globalización. México, D.F.: Editorial Siglo XXI. Impreso.

Lee, Eun-Ja. "China's boxer uprising: its history and myth." Peasant movements and anti-invasion campaigns in the transition to the modern period. Seúl: Sung Kyun Kwan University, 2014. Impreso.

Le Goff, Jacques. Histoire et mémoire. París: Gallimard, 1985. Impreso.

Martínez Peláez, Severo. Motines de Indios, la violencia colonial en Centroamérica y Chiapas. Guatemala: F \& G editores, 2011. Impreso.

Mazlish, Bruce. "On History Becoming History: World History and New Global History". Memoria y Civilización 4. Massachussets Institute of Technology. Web. 15 de enero de 2015. http://web.mit.edu/newglobalhistory/docs/mazlish-on-historybecoming-history.pdf

Mishra, Sandip K. "British colonialism, Sepoy mutiny of 1857 and peasants in India”. Peasant movements and antiinvasion campaigns in the transition to the modern period. Seúl: Sung Kyun Kwan University, 2014. Impreso.

Tanaka, Michiko (coord.). Historia Minima de Japón. México: El Colegio de México, 2011. Impreso. 
Tao, Jiang. "The Taiping Heavenly Kingdom: Hong Xiuquan and Yang Xiuqing, and their revolution." Peasant movements and anti-invasion campaigns in the transition to the modern period. Seúl: Sung Kyun Kwan University, 2014. Impreso.

Tsutomu, Suda. “Japan's imperialization and its peasant movement development." Peasant movements and anti-invasion campaigns in the transition to the modern period. Seúl: Sung Kyun Kwan University, 2014. Impreso.
Tutino, John. "Global transformations and revolutionary freedom: Haiti and the Bají in the era of independence". Web. 25 mayo de 2010. http://photos. state.gov/libraries/america/475/pdf/ Tutino\%20-\%20Global\%20Transformations $\% 20$ and $\% 20$ Revolutionary\%20Freedoms.pdf

Yim, Hyun-Jin. "Korea's early modern times and Donghak revolution." Peasant movements and anti-invasion campaigns in the transition to the modern period. Seúl: Sung Kyun Kwan University, 2014. Impreso. 